10

\title{
Спектральные оптические свойства полимерных композитных наноматериалов на основе углеродных нанотрубок в матрице полиэтилена высокой плотности
}

\author{
(C) Н.М. Ушаков ${ }^{1}$, М.Ю. Васильков ${ }^{1,2}$, В.Р. Шатурный ${ }^{1,3}$, И.Д. Кособудский ${ }^{1,2}$ \\ ${ }^{1}$ Институт радиотехники и электроники им. В.А. Котельникова РАН, Саратовский фрилиал, \\ 410019 Саратов, Россия \\ ${ }^{2}$ Государственный технический университет им. Гагарина Ю.А., \\ 410054 Саратов, Россия \\ ${ }^{3}$ Национальный исследовательский университет имени Н.Г. Чернышевского, \\ 410012 Саратов, Россия \\ e-mail: nmu@bk.ru
}

Поступила в редакцию 12.04.2018 г.

\begin{abstract}
Измерены спектральные оптические характеристики полимерных композитных наноматериалов на основе углеродных нанотрубок (УНТ) в матрице полиэтилена высокой плотности (ПЭВП). Проведено сопоставление полученных экспериментальных данных с расчётными данными. В качестве теоретической модели предложено использовать одночастотную модель осциллятора Лоренца. Показано, что образцы с концентрацией углеродных нанотрубок 10 mass\% в матрице полиэтилена высокой плотности обеспечивают высокое оптическое поглощение 90\% во всём измеряемом диапазоне от 300 до $800 \mathrm{~nm}$. Полимерные композитные наноматериалы на основе УНТ-ПЭВП могут найти практическое применение в различных устройствах ослабления оптического излучения и фотоакустики.
\end{abstract}

DOI: $10.21883 / O S .2018 .11 .46822 .106-18$

\section{Введение}

Полимеры, которые реагируют на внешние воздействия, такие как электрическое и магнитное поле, изменяя форму или размер, считаются интеллектуальными или активными полимерами. Существуют различные типы активных полимеров с различными контролируемыми свойствами. Среди них полимеры, которые изменяют форму и размер в ответ на электрическое воздействие, называются электроактивными полимерами [1]. Некоторые из перспективных электроактивных полимеров представляют собой ионные полимерные гели, электропроводящие полимеры, углеродные нанотрубки, электрострикционные эластомеры, электрострикционные полимеры, сегнетоэлектрические полимеры ит.д. Электроактивные полимеры, обладающие сравнительно высокой электропроводностью, получили название „органические металлы“ [2]. Такие материалы изначально появились в конце 1970-х годов и играют важную роль в органической электронике. Они нашли применение в электрохимических транзисторах [3], фотовольтаических устройствах [4], солнечных элементах [5], сенсорных экранах [6] и т.д.

Большой научный интерес представляет изучение электронных и оптических свойств различных композиций из электроактивных полимеров, образующих супрамолекулярные ансамбли. В работе [7] проведены исследования свойств электропроводящих полимер-сегнетоэлектрических жидкокристаллических композитов. Показано, что свойства композитов сильно зависят от комбинации сегнетоэлектрического жидкого кристалла и проводящего полимера. В этих композитах обнаружены характерные сегнетоэлектрические свойства. Спонтанная поляризация заметно уменьшается с увеличением концентрации проводящего полимера выше примерно $10 \%$, что объясняется учетом микроструктуры композита и перколяционной модели. Также обнаружены электрооптические эффекты, такие как режим переходного рассеяния. Уникальным акцептором в супрамолекулярных ансамблях при создании фотовольтаических ячеек явился фуллерен (Fu) [8]. Большой размер и сферическая форма его молекул, пирамидизация атомов углерода обусловливают их высокое сродство к электрону. При фотовозбуждении композита полимер-Fu скорость переноса электрона на фуллерен меньше $10^{-12} \mathrm{~s}$ и образуется возбужденный комплекс с последующим переходом в состояние с разделенными носителями заряда.

Для образования устойчивой супрамолекулярной системы необходимо выполнение условия механического перемещения в пространстве (трансляционная или/и вращательная диффузия) её компонентов. В твердом теле образование супрамолекулярных систем возможно только в особых случаях: при наличии в твердом теле свободного объема или при пластической деформации твердого тела [9]. Прекрасными материалами, на наш взгляд, для роли „хозяина“ в супрамолекулярном ансамбле могут выступать такие полимеры, как полиэтилен низкой и высокой плотности, которые способны переходить в состояние пластической деформации при температурах около $120^{\circ} \mathrm{C}$ и выше. В работе [10] сообщается о 
новом светопреобразующем композитном материале на основе полиэтиленовой пленки, легированной комплексом [Eu (Phen) $\left.2\left(\mathrm{NO}_{3}\right) 3\right]$. Пленка поглощает УФ излучение в широком диапазоне $320-370 \mathrm{~nm}$ и излучает при $\lambda=611 \mathrm{~nm}$. Полимерная пленка из полиэтилена низкой плотности была выбрана в качестве материала полимерной матрицы. Присадка $\left[\mathrm{Eu}(\mathrm{Phen}) 2\left(\mathrm{NO}_{3}\right) \dot{3}\right]$ была образована путем реакции нитрата европия с 1,10-фенантролином. На наш взгляд, полимерные композиции из полиэтиленовой матрицы с электропроводящими наполнителями представляют собой важные объекты исследования в качестве перспективных материалов фотоники. Исследования спектральных оптических свойств полимерных композитных наноматериалов на основе полиэтилена низкой плотности (ПЭНП) (высокого давления, ПЭВД) с различными напонителями в виде металлических и полупроводниковых наночастиц были проведены в ряде работ $[11,12]$. В отличие от ПЭНП использование полиэтилена высокой плотности (ПЭВП) в качестве матрицы для оптических приложений может обеспечить лучшую оптическую прозрачность. Использование углеродных нанотрубок в качестве наполнителя ПЭВП должно существенно повлиять на его электронные и оптические свойства.

Целью данной работы явилось исследование спектральных оптических характеристик полимерных композитных наноматериалов на основе углеродных нанотрубок в матрице ПЭВП.

\section{Эксперимент}

\section{Материалы}

Для синтеза полимерного композитного наноматериала в качестве матрицы был использован сверхвысокомолекулярный ПЭВП (UHMWPE) (CAS 9002-884, Sigma-Aldrich, США). В качестве наполнителя был использован раствор углеродных нанотрубок (УНТ) в трипропиленгликоль диакрилате (BYK-LP X 21791, BYK-Chemie GmbH, Германия). Для получения композиционных материалов применялись многостенные УНТ в виде $1 \%$-дисперсии в растворе трипропиленгликоль диакрилата $(\rho 20=1.044 \mathrm{~g} / \mathrm{ml})$ коммерческого производства (BYK LP-X 21791). Информации о способе получения данных УНТ производитель не указывает. Предполагается, что УНТ существуют в растворе в виде отдельных пучков.

Количественной мерой наполнителя в матрице ПЭВП являлась его массовая концентрация. Была выбрана концентрация УНТ, равная 10 mass\%. При такой концентрации сохранялась пластичность изготовленных толстоплёночных образцов.

\section{Технология получения}

Получение композиционных материалов на основе ПЭВП, модифицированного углеродными нанотрубками в массовой концентрации $10 \%$, происходило по методике, аналогичной [13]. Для этого навеску сверхвысокомолекулярного ПЭВП постепенно растворяли при умеренном перемешивании в разогретом до $(210 \pm 5)^{\circ} \mathrm{C}$ вакуумном масле. По окончании введения раствора УНТ для равномерного распределения модификатора в полимерной матрице и стабилизации полученного композита смесь дополнительно перемешивалась, после чего охлаждалась до комнатной температуры и очищалась от остатков масла. На заключительной стадии очищенные образцы белого цвета высушивались на воздухе и механически диспергировались в ступке до порошкообразного состояния. Для проведения дальнейших измерений из порошков композитов методом термопрессования при температуре $(180 \pm 10)^{\circ} \mathrm{C}$ и давлении $1-2$ bar изготавливали пленки толщиной 150-250 $\mu \mathrm{m}$.

\section{Характеризация}

Морфология поверхности образцов композитов была изучена методом сканирующей электронной микроскопии (СЭМ) на двухлучевой рабочей станции CarlZeiss AURIGA (CrossBeam (Carl Zeiss Group, Germany) c автоэмиссионным катодом из $\mathrm{Ga}$ (галлия) при ускоряющих напряжениях электронного потока $5-10 \mathrm{kV}$ и давлении $(6.4-6.7) \cdot 10^{-8} \mathrm{~Pa}$ в режиме вторичных электронов. Спектральный рентгеновский фазовый анализ (РФА) проводился на рентгеновском дифрактометpe ARL X'TRA X-ray Diffractometer (Thermo Fischer Scientific, USA) (Cu K $\alpha$-монохроматор, 1,54 $\AA$ ) в диапазоне углов от $5^{\circ}$ до $60^{\circ}$ с шагом $0.02^{\circ}$. Результаты измерений представлены на рис. $1, d$.

Углеродные нанотрубки в качестве модификатора представляют собой полые цилиндрические структуры диаметром 40-50 nm и длиной от 1 до нескольких $\mu \mathrm{m}$. Плотная упаковка трубок за счет значительной гибкости и высокого аспектного соотношения позволяет модифицировать полимерную матрицу с высокой степенью заполнения, что видно на оптической фотографии композита (рис. $1, b)$ по сплошной черной окраске.

Спектральные данные РФА приведены на рис. 1, $d$. На спектре как чистого ПЭВП, так и с добавкой УНТ, присутствуют характеристические узкие пики высокой интенсивности при $2 \theta=21.9^{\circ}, 24.3^{\circ}, 36.6^{\circ}$, которые соответствуют высокомолекулярному полиэтилену с общей формулой $\left(\mathrm{C}_{2} \mathrm{H}_{4}\right)_{n}, n>10^{5}$ (Crystallographica Search-Match, № 000-60-1505). На спектре модифицированного УНТ полиэтилена наблюдается появление малоинтенсивного пика при $40.2^{\circ}$ и широкополосного при $19.9^{\circ}$. Низкая интенсивность углеродных пиков связана с невысокой концентрацией УНТ в полимерной матрице и недостаточным их количеством в приповерхностном слое образца. 

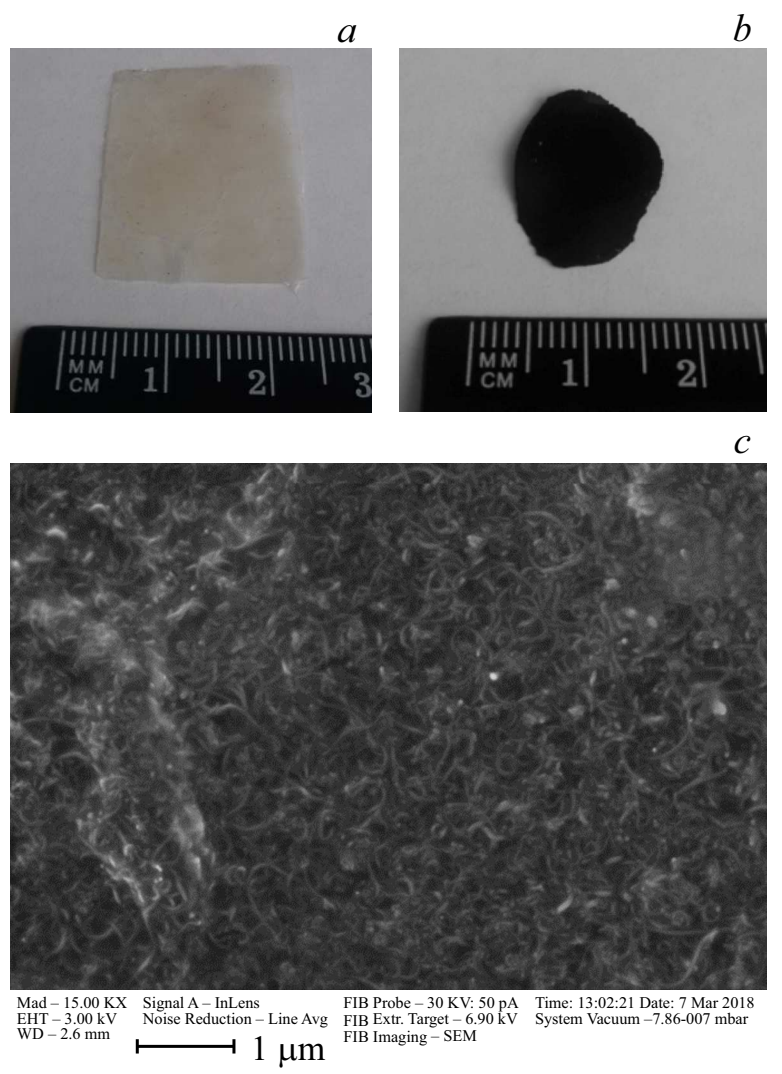
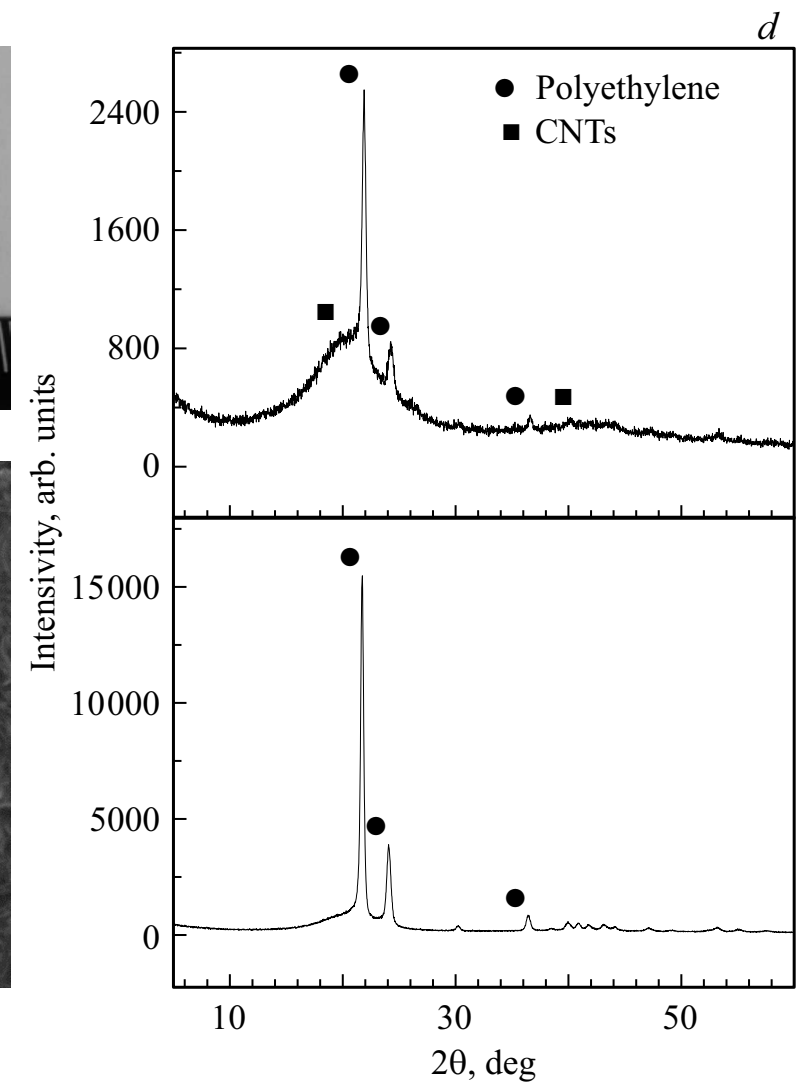

Рис. 1. Оптические фотографии пленок чистого ПЭВП (a) и композита на его основе, модифицированного УНТ $(b)$. СЭМмикрофотография поверхности алюминиевой подложки со слоем УНТ (c). Спектры РФА образцов немодифицированного ПЭВП (нижняя панель) и полимера с добавкой 10 mass\%-УНТ (верхняя панель) $(d)$.

\section{Спектральные оптические измерения}

Для исследования оптических спектральных характеристик полимерных нанокомпозитов была выбрана двухпотоковая модель Кубелки-Мунка [14]. Одним из существенных преимуществ данной модели является использование некогерентного источника излучения, перестраиваемого по длине волны в широком диапазоне. В данной работе спектральные измерения проводились с помощью спектрофотометра Lambda-950 (USA) c интегрирующей сферой в диапазоне оптических длин волн от 300 до $900 \mathrm{~nm}$.

Любые три измерения из последующих пяти вариантов достаточны для определения основных оптических параметров - отражения, пропускания и экстинкции (поглощение и рассеяние): 1) полное $(T)$ или диффузное пропускание $\left.\left(T_{d}\right), 2\right)$ диффузное отражение $\left(R_{d}\right)$, $3)$ поглощение образца, 4) коллимированное пропускание $\left.\left(T_{c}\right), 5\right)$ угловое распределение рассеянного образцом излучения. В нашем случае было выбрано измерение коллимированного и полного пропускания $\left(T=T_{c}+T_{d}\right)$, а также диффузного отражения монохроматического излучения исследуемого образца.
Показатели преломления $(n)$ и коэффициент экстинкции $(k)$ находятся из известных соотношений [14]:

$$
\begin{gathered}
n=\frac{1+R_{d}+\sqrt{4 R_{d}-k^{2}\left(1-R_{d}\right)^{2}},}{1-R_{d}}, \\
k=\frac{\lambda \mu_{a}}{4 \pi},
\end{gathered}
$$

где $R_{d}$ - коэффициент диффузного отражения, $\mu_{a}$ коэффициент поглощения $[1 / \mathrm{m}] ; \lambda-$ длина волны света $[\mathrm{m}]$.

Показатели преломления и поглощения в комплексной среде определяются диэлектрическими и омическими потерями электромагнитных волн в ней. Имея измеренные величины $n$ и $k$, можно оценить удельную проводимость образцов на оптических частотах $\sigma$ как $\sigma=2 n k \omega \varepsilon_{0}$, где $\omega=2 \pi / \lambda-$ круговая частота $[\mathrm{Hz}]$, $c=3 \cdot 10^{8}-$ скорость света в вакууме $[\mathrm{m} / \mathrm{s}]$.

\section{Результаты и их обсуждение}

Характерной особенностью образцов ПЭВП, модифицированных 10 mass\%-УНТ, как и ожидалось, явилось высокое оптическое поглощение в исследуемом 


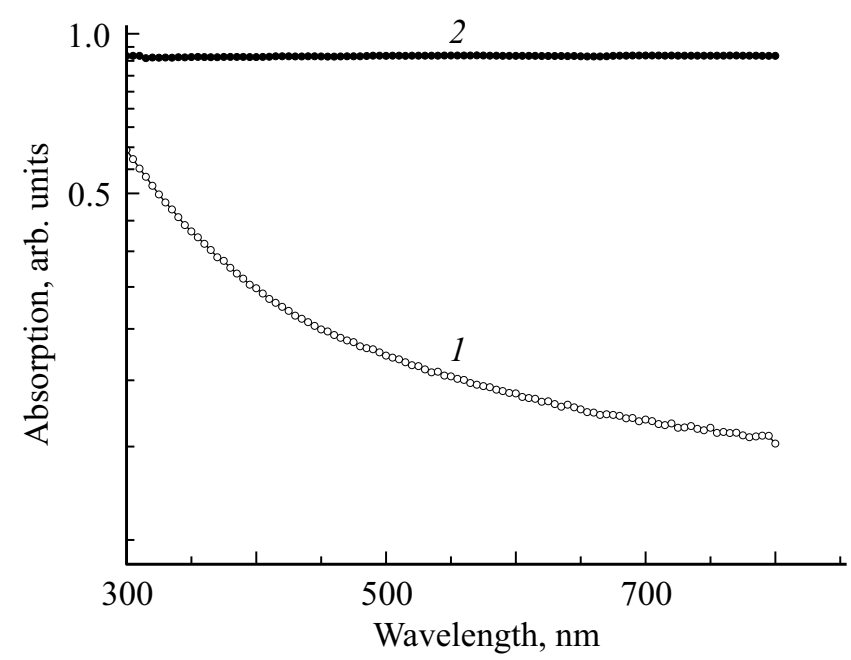

Рис. 2. Спектральные зависимости оптических потерь образцов чистого ПЭВП (1) и модифицированного $10 \mathrm{mass} \%$ УНT (2).

диапазоне длин волн от 300 до $800 \mathrm{~nm}$. На рис. 2 показаны спектральные зависимости оптических потерь (поглощение и рассеяние света) в образцах чистого ПЭВП (кривая 1) и модифицированного 10 mass\%-УНТ (кривая 2). Причем следует отметить практически постоянное значение оптических потерь на всех длинах волн, равное $90 \pm 1 \%$, для образцов полиэтилена, модифицированного $10 \%$ mass \%-УНТ. Оптические потери чистого полиэтилена составляют в видимой и ближней ИК области спектра от 31 до 17\% с тенденцией роста прозрачности в ИК области. Постоянство оптических потерь в диапазоне от 300 до $800 \mathrm{~nm}$ для модифицированного полиэтилена обусловлено тем, что уменьшение коэффициента поглощения от 77 до $65 \mathrm{~cm}^{-1}$ компенсируется ростом коэффициента рассеяния от 96 до $150 \mathrm{~cm}^{-1}$.

Хорошее феноменологическое объяснение зависимостей оптических показателей преломления и поглощения от длины волны в средах с высокой электропроводностью - ионных кристаллах, проводящих полимерах ит.д., можно получить исходя из классической теории Лоренца, в которой твердое тело рассматривается как совокупность осцилляторов, совершающих вынужденные колебания под действием оптического излучения $[15,16]$. Итак, пусть под действием поля падающей электромагнитной волны $e E_{x} e^{i \omega t}$ электроны с зарядом $e$ и массой $m$ периодически смещаются на расстояние $x$.

На электроны действуют тормозящая сила $m \Gamma d x / d t$ и возвращающая сила $m \omega_{0}^{2} x$, где $\omega_{0}-$ угловая резонансная частота, $\Gamma$ - параметр затухания колебаний осциллятора. Уравнение движения электрона можно записать в форме

$$
m \frac{d^{2} x}{d t^{2}}+m \Gamma \frac{d x}{d t}+m \omega_{0}^{2} x=-e E_{x} e^{i \omega t}
$$

Амплитудное значение синусоидального смещения электрона как решение уравнения (3) можно записать в виде

$$
x_{0}=\frac{-e E_{x} / m}{\omega_{0}^{2}-\omega^{2}-i \omega \Gamma} .
$$

На основании материальных уравнений Максвелла $\varepsilon \varepsilon_{0} E=\varepsilon_{0} E+P$, где $P=-e N x_{0}, N-$ объёмная концентрация электронов, $\varepsilon_{0}=8.85 \cdot 10^{-12} \mathrm{~F} / \mathrm{m}-$ диэлектрическая проницаемость вакуума и соотношения $\varepsilon=1-e N x_{0} / \varepsilon_{0} E_{x}$ нетрудно получить, что

$$
\varepsilon=(n-i k)^{2}=1+\frac{e^{2} N / m e_{0}}{\omega_{0}^{2}-\omega^{2}-i \omega \Gamma} .
$$

Разделяя вещественную и мнимую части в (4), получаем для показателей преломления и коэффициента экстинкции следующие соотношения:

$$
\begin{gathered}
\varepsilon_{1}(\omega)=n^{2}-k^{2}-1=\left(\frac{e^{2} N}{m \varepsilon_{0}}\right) \frac{\omega_{0}^{2}-\omega^{2}}{\left(\omega_{0}^{2}-\omega^{2}\right)^{2}+\omega^{2} \Gamma^{2}}, \\
\varepsilon_{2}(\omega)=2 n k=\left(\frac{e^{2} N}{m \varepsilon_{0}}\right) \frac{\omega \Gamma}{\left(\omega_{0}^{2}-\omega^{2}\right)^{2}+\omega^{2} \Gamma^{2}} .
\end{gathered}
$$

В более общем виде выражение (5) имеет вид

$$
n^{2}-k^{2}-\varepsilon^{*}=\left(\frac{e^{2} N}{m \varepsilon_{0}}\right) \frac{\omega_{0}^{2}-\omega^{2}}{\left(\omega_{0}^{2}-\omega^{2}\right)^{2}+\omega^{2} \Gamma^{2}},
$$

где $\varepsilon^{*}=1$ в полосе электронного поглощения и $\varepsilon^{*}=n_{0}^{2}$ на частотах ниже этой области поглощения.

Резонансная частота $\omega_{0}$ представляет собой частоту, на которой проводимость среды $2 n k \omega$ достигает максимума, параметр $\Gamma$ - характеризует полуширину этого максимума. Спектральные зависимости $k=k(\omega)$ и $n=n(\omega)$ также имеют максимумы (не показаны), но смещены незначительно относительно резонансной частоты. Оценки значения резонансной круговой частоты показали, что для полиэтилена, модифицированного 10 mass\%-УНТ, значения этой частоты примерно равны $400 \mathrm{THz}$ и находятся в средней области ИК диапазона $(\lambda=4.7 \mu \mathrm{m})$.

Спектральные зависимости показателя преломления $n=n(\lambda)$ коэффициента экстинкции $k=k(\lambda)$ для модифицированного полиэтилена показаны на рис. 3. Для сравнения на рис. 3, $a, b$ приведены соответствующие теоретические зависимости (кривая 2). Расчеты спектральных характеристик показателей преломления и поглощения проведены для следующих значений параметров: $\omega_{0}=400 \mathrm{THz}, N=2 \cdot 10^{26} \mathrm{~m}^{-3}, \Gamma / \omega_{0}=0.1$, $n_{0}=1.49$. Сравнение расчетных и экспериментальных данных на рис. 3 показало, что максимальное расхождение экспериментальных данных для показателя преломления и данных расчёта по классической модели Лоренца не превосходят $1.5 \%$, но формы кривых различны. Спектральные зависимости показателя поглощения на рис. $3, b$ отличаются крутизной изменения в диапазоне 

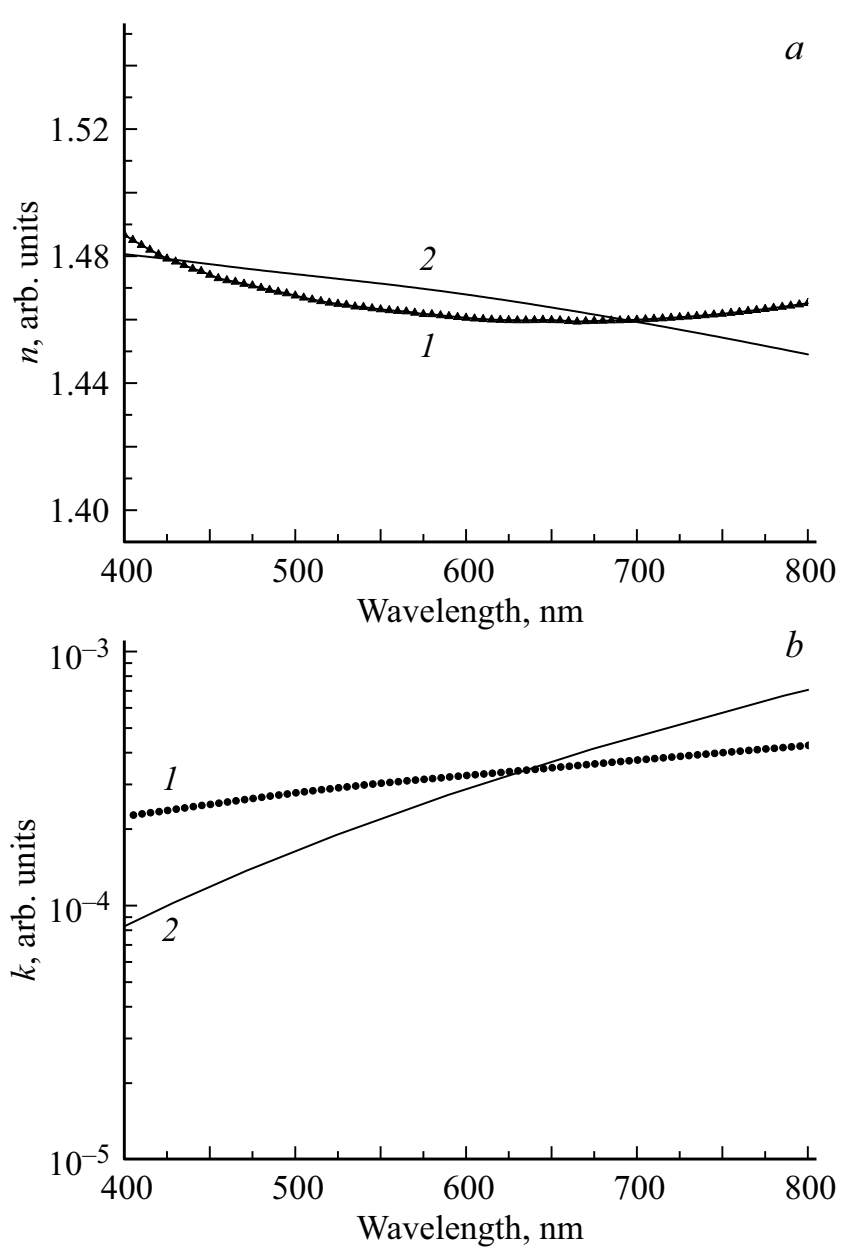

Рис. 3. Спектральные зависимости (a) показателя преломления $(1)$ и $(b)$, коэффициента экстинкции $(1)$ образцов ПЭВП, модифицированного 10 mass\%-УНТ; 2 - соответствующие расчетные зависимости.

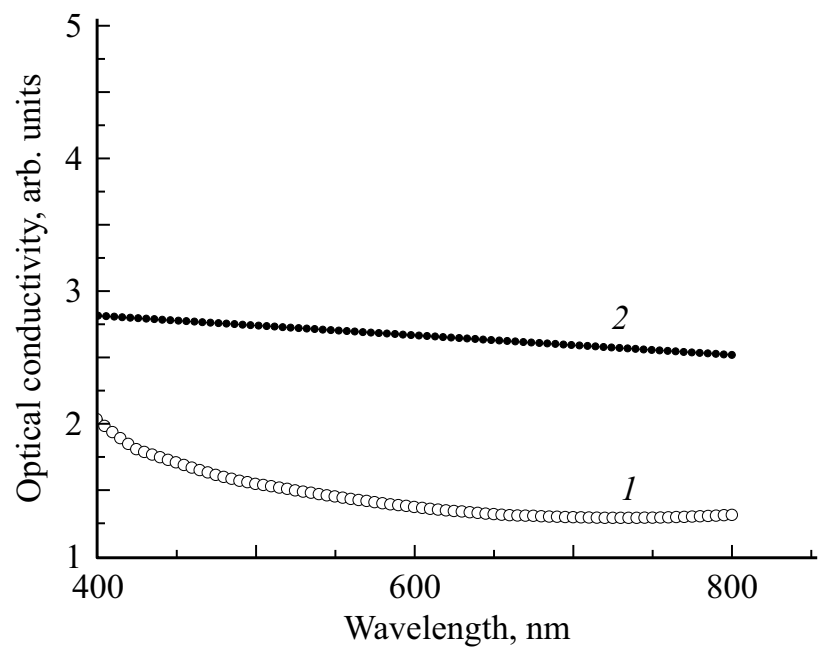

Pис. 4. Спектральные зависимости оптической удельной проводимости образцов чистого ПЭВП (1) и модифицированного 10 mass\%-УHT (2). от 400 до $800 \mathrm{~nm}$. Для более точного расчета спектральных зависимостей показателей преломления и поглощения можно использовать квантово-механический подход теории дисперсии, в котором рассматривается не один осциллятор с одной резонансной частотой, а набор осцилляторов со своими заданными резонансными частотами и силами осцилляторов [16].

Оптические свойства проводящих полимеров удобно описывать с помощью комплексной оптической проводимости $\sigma(\omega)=\sigma_{1}(\omega)-i \sigma_{2}(\omega)$, где оптическая мощность поглощения в среде $P_{a}(\omega) \sim \sigma_{1}(\omega)\left\langle E^{2}\right\rangle$, а $E-$ амплитуда электрического поля волны. Следует отметить, что на нулевой частоте $\omega=0$ оптическая удельная проводимость равна электрической удельной проводимости среды. На рис. 4 показаны спектральные зависимости оптической удельной проводимости образцов чистого полиэтилена высокой плотности (кривая 1) и модифицированного 10 mass\%-УНТ (кривая 2). Как следует из приведенных зависимостей, оптическая удельная проводимость модифицированного полиэтилена превосходит проводимость чистого полиэтилена в 1.5-2.5 раза в диапазоне от 400 до $600 \mathrm{~nm}$. Высокая поглощаемая мощность в модифицированном полиэтилене соответствуют общим оптическим потерям, показанным на рис. 1.

\section{Заключение}

Использование модели одночастотного осциллятора Лоренца для описания основных оптических свойств ПЭВП, модифицированного 10 mass\%-УНТ, показало удовлетворительную совместимость теории с экспериментом. Показано, что модифицированный полиэтилен даже со средним уровнем массовой концентрации УНТ обеспечивает высокую оптическую поглощательную способность материала в диапазоне длин волн 300-800 nm. Данная особенность модифицированного ПЭВП может найти практическое применение в различных устройствах ослабления оптического излучения и фотоакустики.

\section{Список литературы}

[1] Lee K., Cho S., Park S.H., Heeger A.J. et al. // Nature. 2006. V. 441. P. 65-68.

[2] Shirakawa H. // Ang. Chemie Int. Ed. 2001. V. 40. P. 2574.

[3] Hempel F., Law J.K.-Y., Nguyen T.C. et al. // Biosens. Bioelectron. 2017. V. 93. P. 132.

[4] Lee S.J., Kim H.P., A.R. bin Mohd Yusoff, Jang J. // Sol. En. Mater. Sol. Cells. 2014. V. 120. P. 238.

[5] Ho K.-Y., Li C.-K., Syu H.-J. // J. Appl. Phys. 2016. V. 120. P. 215501. doi 10.1063/1.4970827

[6] Kim B.-J., Han S.-H., Park J.-S. // Thin Solid Films. 2014. V. 572. P. 68.

[7] Xiao Hong Yin, Masanori Ozaki, Katsumi Yoshino // Jap. J. Appl. Phys. 1993. V. 32. Part 1. N 9B. P. 4348

[8] Feldapp K., Brutting W., Schwoerer M. et al. // Synth. Met. 1999. V. 101. P. 156. 
[9] Dodziuk H. Introduction to Supramolecular Chemistry. Springer, 2002.

[10] Pogreb R., Finkelshtein B., Shmukler Yu. et al. // Polymers for Adv. Technol. 2004. V. 15. P. 414.

[11] Ушаков Н.М., Кочубей В.И., Запсис К.В., Кособудский И.Д. // Опт. и спектр. 2004. Т. 96. № 5. С. 874; Ushakov N.M., Kochubey V.I., Zapsis K.V., Kosobudsky I.D. // Opt. Spectrosc. 2004. V. 96. N 5. P. 798.

[12] Ушаков Н.М., Юрков Г.Ю., Запсис К.В. и др. // Опт. и спектр. 2006. Т. 100. № 3. С. 459; Ushakov N.M., Yurkov G.Yu., Zapsis K.V. et al. // Opt. Spectrosc. 2006. V. 100. N 3. P. 414.

[13] Gubin S.P., Yurkov G.Yu., Kosobudsky I.D. // Polymer. Intern. J. Mater. Product Technol. 2005. V. 23. P. 2-25. doi 10.1504/IJMPT.2005.006587

[14] Cheong W.-F., Scott A.P., Welch A.J. // IEEE J. Quant. Electron. 1990. V. 26. P. 2166.

[15] Moss T.S., Burrell G.J., Ellis B. Semiconductor OptoElectronics. Butterworth \& Co. (Publishers) Ltd., 1973; Перевод: Мосс Т., Баррел Г., Эллис Б. Полупроводниковая оптоэлектроника. М: Мир, 1976. $431 \mathrm{c}$.

[16] Ribbing C.G. Introduction to Material Optics, a Compendium. 2002. Uppsala University, Sweden. 